\title{
PENGEMBANGAN PENGELOLAAN PEMBELAJARAN EKONOMI BERBASIS LINGKUNGAN DENGAN STRATEGI SMALL GRAUP DISCUSSION DI SMA MUHAMMADIYAH 1 SURAKARTA
}

\author{
Oleh: \\ Ahmad Nasir Ari Bowo \\ Universitas Cokroaminoto Yogyakarta
}

\begin{abstract}
Abstrak
Latar belakang dalam penelitian ini adalah masih banyaknya guru dalam melaksanakan proses pembelajaran dengan siswa, kurang memaksimalkan media dan sumber belajar secara maksimal. Selain itu guru masih monoton dalam menyampaikan materi. Strategi pembelajaran yang diterapkan kebanyakan masih menggunakan ceramah, sehingga banyak siswa yang jenuh dan bosan dalam mengikuti pembelajaran. Apabila hal tersebut terus terjadi, maka akan berdampak pada dunia pendidikan, yaitu bahwa tujuan pendidikan tidak tercapai dengan maksimal. hal itu juga terjadi di SMA Muhammadiyah 1 Surakarta.

Tujuan penelitian ini adalah untuk mewujudkan pembelajaran yang menyenangkan melalui pengembangan model pembelajaran ekonomi berbasis lingkungan di SMA Muhammadiyah 1 Surakarta. Jenis penelitian adalah research and development dan eksperimen. Guru dan siswa kelas x sebagai populasi pelaksanaan uji coba. Tahapan pengembangan melalui pendekatan deskriptif kualitatif. Meliputi 1) studi pendahuluan, 2) pengembangan, dan 3) pengujian.

Hasil penelitian 1) pengembangan pengelolaan pembelajaran ekonomi berbasis lingkungan dengan strategi small group discussion. Langkah-langkah model tersebut yaitu a) pendahuluan, b) penyajian materi substantive, c) mengajukan, membandingkan dan menjelaskan analogi, d) pengujian tim, e) implementasi kelompok, f) pengujian analogi baru, dan g) penutup. Dapat diketahui bahwa, terdapat peningkatan pemahaman konsep dan prestasi akademik melalui implementasi model pembelajaran ekonomi berbasis lingkungan materi lembaga bank dan non bank dengan strategi small group discussion di SMA Muhammadiyah 1 Surakarta.
\end{abstract}

Kata kunci: pengelolaan pembelajaran, small group discussion, perubahan perilaku.

\section{Pendahuluan}

Proses pembelajaran berhasil atau tidaknya sangat di tentukan oleh guru. Pengelolaan dan strategi pembelajaran oleh guru sangatlah penting untuk menciptakan suasana pembelajaran aktif, inovatif, kreatif, efesien, dan menyenangkan, sehingga peserta didik tidak jenuh dan dapat dengan mudah memahami materi. Proses pembelajaran seharusnya tidak hanya dilaksanakan 
dikelas saja. Akan tetapi dapat dilaksanakan dilingkungan manapun. Lingkungan belajar yang kondusif dapat menumbuh kembangkan motif untuk belajar dengan baik dan produktif.

Hasil wawancara peneliti dengan siswa yang mengikuti pembelajaran ekonomi di SMA Muhammadiyah 1 Surakarta, dapat disimpulkan bahwa masih ada guru dalam mengajar belum memanfaatkan lingkungan sebagai media atau sumber pembelajaran secara maksimal. Selain itu strategi pembelajaran yang sering di gunakan adalah ceramah bervariasi, sehingga masih ada siswa yang kurang aktif dalam mengikuti pembelajaran, bahkan ada yang merasa jenuh dan mengantuk, ketika mengikuti pembelajaran. Dapat diketahui bahwa tujuan pembelajaran ekonomi di SMA Muhammadiyah 1 Surakarta belum tercapai secara maksimal. Sehi ${ }^{2}$ a perlu ada pengembangan pengelolaan dan strategi pembelajaran. Hal tersebut bertujuan untuk memudahkan siswa dalam mencapai tujuan pembelajaran.

Berdasarkan latar belakang masalah tersbut peneliti mencoba melakukan penelitian tentang pengembangan pengelolaan pembelajaran berbasis lingkungan dengan strategi small goup discussion di SMA Muhammadiyah 1 Surakarta. Penelitian ini bertujuan untuk: 1) mendeskripsikan pengelolaan pembelajaran ekonomi yang dilaksanakan oleh guru SMA Muhammadiyah 1 Surakarta. 2) mendiskripsikan pengembangan model pembelajaran ekonomi berbasis lingkungan dengan strategi small group discussion di SMA Muhammadiyah 1 Surakarta. 3) mendiskripsikan implementasi model pembelajaran ekonomi berbasis lingkungan dengan strategi small group discussion di SMA Muhammadiyah 1 Surakarta. 4) menguji dan membandingkan perbedaan pemahaman konsep dapa mata pelajaran ekonomi yang pembelajarannya berbasis lingkungan dengan strategi small group discussion di SMA Muhammadiyah 1 Surakarta. 5) menguji dan membandingkan prestasi akademik pada mata pelajaran ekonomi yang pembelajarannya berbasis lingkungan dengan strategi small group discussion di SMA Muhammadiyah 1 Surakarta.

Banyak penelitian yang berkaitan tentang model pengembangan pembelajaran, pengembangan kurikulum, dan pengembangan materi ajar. Model pengembangan tersebut sangatlah beragam. Hasil penelitian Chien dkk. (2009), dapat disimpulkan bahwa kegiatan pembelajaran dapat meningkatkan kinerja ilmiah siswa, termasuk pengetahuan dan tingkat pemahaman. Persepsi mahasiswa dari 
kegiatan belajar ini tampaknya positif. Studi ini mengidentifikasi dua faktor yang menonjol dalam efek positif: siswa terlibat dalam "mobile-teknologi yang didukung" pengamatan selama penyelidikan ilmiah mereka; dan siswa terlibat dalam "mobile-teknologi yang didukung" manipulasi selama penyelidikan ilmiah mereka. Akhirnya, kesimpulan bahwa penelitian kami telah menarik bisa merupakan panduan yang berguna bagi praktisi pendidikan yang bersangkutan dengan potensi komputasi mobile di sekolah, (Journal of education, technology and society volume 12 Issue p.344-358). Selain itu hasil penelitian Hasio dkk., (2010) menunjukkan bahwa dalam pembelajaran di suatu sekolah kelompok eksperimen mengungguli kelompok kontrol pada tes pengetahuan ekologi. Selain itu, siswa dalam kelompok eksperimen merasa puas dengan sistem pembelajaran ekologi didukung oleh sistem penentuan posisi. Implikasi pedagogis dari penelitian ini adalah bahwa siswa perlu pengalaman langsung untuk memperoleh pemahaman tentang suatu topik tertentu (Journal of education, technology and society volume 13 Issue 4 p.98-111).

Hasil penelitian tersebut dapat diketahui bahwa pembelajaran dengan menggunakan berbagai media, baik teknologi maupun sumber-sumber lain, dapat meningkatkan pembelajaran yang lebih baik dan maksimal. Persamaan penelitian sebelumnya dengan penelitian ini antara lain sama-sama menerapkan pembelajaran dengan beberapa sumber lingkungan. selain itu pembelajaran tersebut dapat meningkatkan kemampuan peserta didik dalam memahami materi. Selanjutnya

perbedaan antara penelitian ini dengan penelitian terdahulu adalah dalam hal model pembelajaran. Penelitian ini menerapkan berbagai model pembelajaran yang inovatif. Salah satunya adalah menggunakan strategi small group discussion. Model pembelajaran tersebut di kembangkan untuk memudahkan siswa dalam memahami materi.

\section{Metode Penelitian}

Jenis penelitian ini adalah research and development pendekatan eksperimen. Hal tersebut didasarkan pada kenyataan bahwa metode eksperimen merupakan metode yang tepat dan akurat untuk memenuhi fungsi ilmu yaitu menjelaskan, memprediksi, dan mengontrol. Metode eksperimen mempunyai struktur yang paling ketat dan transparan. 
Adapun langkah-langkah modifikasi dalam penelitian ini adalah 1) studi pendahuluan 2) pengembangan, dan 3) pengujian. Penelitian ini berlokasi di SMA Muhammadiyah 1 Surakarta yang beralamat di Jalan RM. Said 35 kota Surakarta Provinsi Jawa Tengah. Subjek dalam pengembangan ini adalah guru dan siswa. Survai awal di pilih kelas X sebanyak 2 jam mata pelajaran dalam satu minggu.

Teknik analisis data yang digunakan yaitu terkait pengelolaan pembelajaran ekonomi berbasis lingkungan di SMA Muhammadiyah 1 Surakarta. Keabsahan data dalam penelitian ini meliputi kualitatif, eksperimen, dan uji T.

\section{Penelitian dan Pembahasan}

\section{A. Pengelolaan pembelajaran ekonomi yang dilaksanakan oleh Guru SMA Muhammadiyah 1 Surakarta.}

Pengelolaan pembelajaran yang dilaksanakan oleh guru mata pelajaran ekonomi SMA Muhammadiyah Surakarta, masih kurang maksimal. Hal tersebut dapat diketahui bahwa rencana pelaksanaan pembelajaran kurang lengkap selama mengajar satu semester. Guru hanya mengandalkan materi buku paket dan modul atau lembar kerja siswa. Pelaksanaan pembelajarn pun juga terkesan monoton terutama guru yang mengajar pada kelas X IPS. Sehingga hasil pembelajarannya pun belum dikatakan berhasil.

\section{B. Pengembangan model pembelajaran ekonomi berbasis lingkungan dengan strategi small group discussion di SMA Muhammadiyah 1 Surakarta \\ Pengembangan model pembelajaran ekonomi berbasis lingkungan pada tahapan pertama} masih ada beberapa sisi kelemahannya. Hal tersebut dapat diketahui pada waktu uji coba model kelas terbatas. pengajar masih belum begitu menguasai konsep model pembelajaran ekonomi berbasis lingkungan. Selanjutnya perlu diadakan evaluasi agar menjadi lebih baik. Selanjutnya pada tahap ujicoba lebih luas pengajar sudah dapat menerapkan model pembelajaran dengan baik. Hal tersebut dapat diketahui dari perubahan pada siswa. 
C. Implementasi model pembelajaran ekonomi berbasis lingkungan dengan strategi smail group discussion di SMA Muhammadiyah 1 Surakarta

Implementasi model pembelajaran ekonomi berbasis lingkungan terlaksana dengan baik, Meskipun perlu evaluasi. Hal tersebut dapat diketahui guru dan peneliti melakukan implementasi model 6 kelas pada jenjang yang sama. Dari hasil implementasi tersebut teryata terdapat perbedaan yang signifikan pada siswa.

D. Pemahaman konsep dan prestasi akademik pada mata pelajaran ekonomi berbasis lingkungan dengan strategi small group discussion di SMA Muhammadiyah 1 Surakarta

Pemahaman konsep ekonomi dan prestasi siswa mengalami peningkatan yang berarti. Ujicoba lebih luas yang dilakukan memberikan hasil yang tidak jauh berbeda, demikian juga pada uji validasi.

\section{Kesimpulan}

\section{A. Perbandingan dengan Hasil Penelitian Terdahulu}

Hasil penelitian Chien dkk. (2009), Witthaus (2009), dan Hasio dkk., (2010) terkait penelitian berbasis lingkungan sebagaimana yang dipaparkan dalam uraian sebelumnya, dapat diketahui bahwa terdapat perbedaan dan persamaan dengan penelitian ini. Adapun persamaan dalam penelitian ini antara lain adalah sama-sama penelitian yang berbasis lingkungan, mempunyai dampak yang signifikan setelah diadakan penelitian, dan penelitian terfokus dalam salah satu bidang. Selanjutnya perbedaannya adalah pada penelitian terdahulu lebih menekankan pada lingkungan

e-learning, mobile teknologi, sedangkan dalam penelitian ini lebih menekankan pada berbagai lingkungan yang meliputi internet, buku, masyarakat, serta berbagai media. Hasil dalam penelitian ini lebih menekankan pada model pembelajaran yang inovatif.

\section{B. Hasil Pengembangan}

Adapun hasil pengembangan pembelajaran ekonomi berbasis lingkungan dengan strategi small group discussion sebagaimana dipaparkan dalam gambar 1 di bawah ini. 


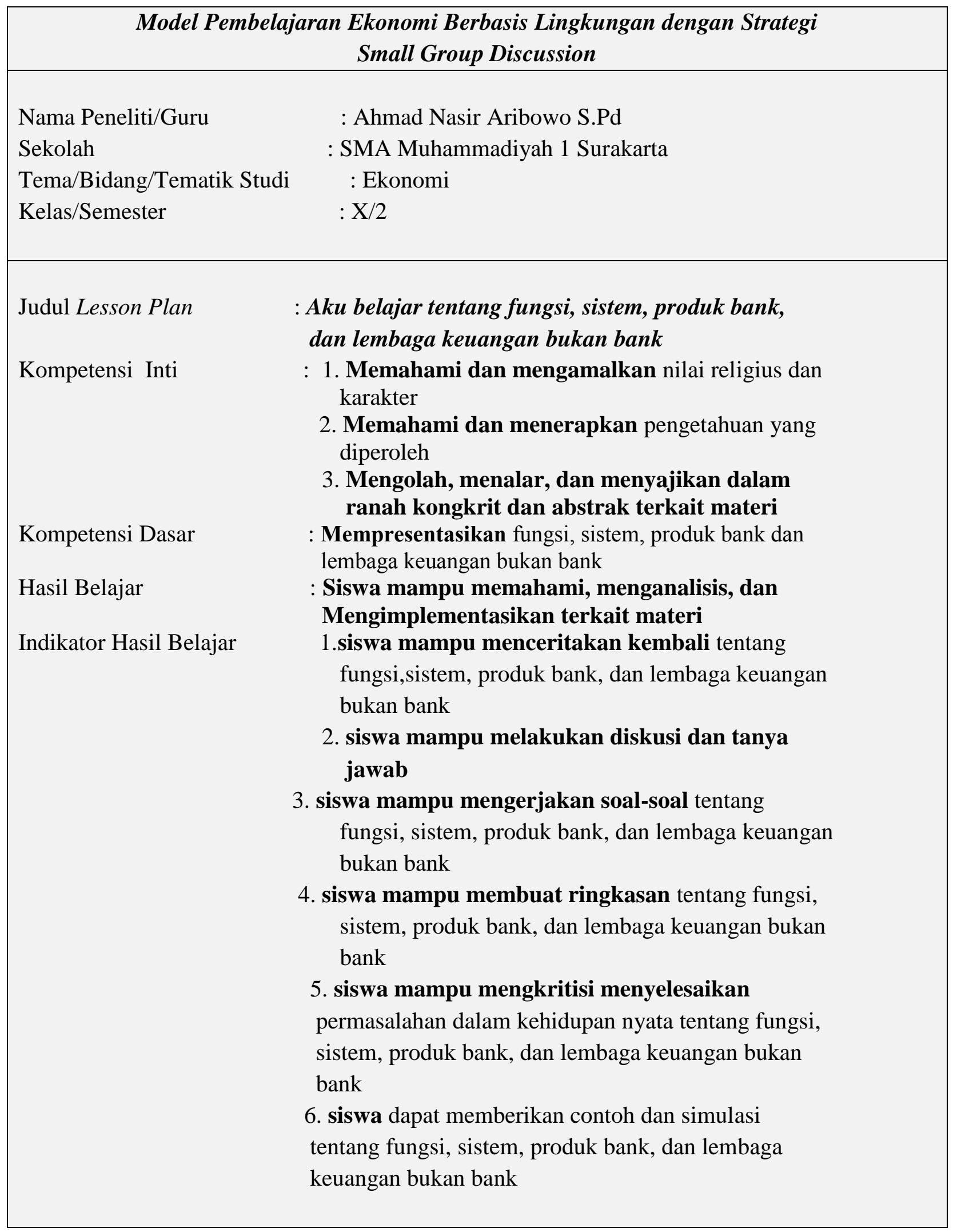




\begin{tabular}{|ll|}
\hline Alokasi Waktu & $\begin{array}{l}\text { : } 1 \text { kali tatap muka. @1 kali tatap muka: } 1 \text { jam } 45 \text { menit } \\
\text { Character Building }\end{array}$ \\
& $\begin{array}{l}\text { 2. Kerja sama } \\
\text { 3. Tolong menolong }\end{array}$ \\
& \\
\hline AKTIVITAS &
\end{tabular}

\section{Tatap Muka 1}

Hari/tgl:

Zona Alfa

Tahap pertama: pendahuluan

1. Salam pembuka dan atau berdo'a (taqwa)

2. Perkenalan (pengakraban, saling mengenal)

3. Ice breaking (video)

4. Absensi dan menanyakan keadaan siswa (empati, peduli, dan disiplin)

5. Apersepsi : memotivasi siswa cerita tokoh (motivasi, inspirasi)

Tahap kedua: penyajian materi substantive

1. Menyatakan tujuan pembelajaran khusus

2. Menyajikan materi baru, dengan teknik penyajian "pembentukan konsep dari Taba".

3. Menguatkan pemahaman siswa
a. Pengertian Bank
b. Perkembangan dan fungsi Bank
c. Jenis-jenis Bank
d. Produk dan jasa perbankan
e. Lembaga keuangan bukan bank

4. Display kelas dan pembagian kelompok

a. Siswa dibagi menjadi lima kelompok

1) Kelompok $A$ membahas tentang pengertian, perkembangan dan fugsi bank.

2) Kelompok B membahas tentang jenis bank, produk, jasa perbankan, dan lembaga keuangan bukan bank.

3) Kelompok $\mathrm{C}$ membahas tentang bank syariah dan bank konvensional

4) Kelompok D dan E membahas tentang topic pada kelompok A, B, dan C

b. Tiga kelompok mendapatkan topik dan atau tema materi yang berbeda, sedangkan dua kelompok medapatkan materi dan topik yang sama (observing, eksplorasi) 
Tahap ketiga: mengajukan, membandingkan, dan menjelaskan analogi

1. Mengajukan analogi langsung (apa yang kamu ketahui tentang lembaga bank dan bukan bank), meminta siswa mendiskripsikan sesuatu yang dianalogikan (mengapa disebut bank konvensional dan mengapa disebut bank syariah apa perbedaanya), mendorong siswa untuk berani mengemukakan pendapat sesuai topik dan atau tema yang diinstruksikan (eksplorasi, elaburasi)

2. Meminta siswa membandingkan kaitan antara aspek-aspek dalam materi yang sedang dibahas dengan aspek yang ada dalam obyek atau kegiatan yang dianalogikan ( bagaimana implementasinya dalam kehidupan nyata terkait bank dan bukan bank) (eksplorasi, elaburasi)

3. Meminta siswa menjelaskan hasil yang dianalogikan dan merangkumnya (eksplorasi, elaburasi, konfrimasi)

\section{Tahap keempat: Analogi tim}

1. Meminta dan mendorong kelompok siswa mengajukan analogi (eksplorasi)

2. Meminta kolompok siswa mendiskusikan tema dan atau topik materi (elaburasi)

3. Meminta kelompok siswa merangkum hasil diskusi (eksplorasi, elaburasi)

\section{Tahap kelima: Implementasi kelompok (materi yang dibahas)}

1. Meminta tiga kelompok siswa secara bergantian mempresentasikan dan atau simulasi didepan kelas materi yang baru saja di bahas, selanjutnya kelompok lain atau dua kelompok menanggapi materi yang dipresentasikan, dan mendiskusikan bersama apabila ada materi yang belum dipahami, hal tersebut dilakukan secara bergantian (eksplorasi, elaburasi, konfirmasi, questioning, eksperimenting)

2. Merangkum hasil diskusi kelompok (konfirmasi)

\section{Tahap keenam: mengajukan analogi baru}

1. Meminta siswa mengajukan analogi baru terhadap materi yang sedang di bahas

2. Mendorong siswa agar bisa membuat analogi baru (eksplorasi)

3. Meminta siswa menjelaskan persamaan dan perbedaan antara aspek-aspek yang ada dalam materi yang sedang dibahas dengan obyek atau kegiatan yang dianalogikan (elaburasi, konfirmasi)

4. Merangkum hasil analogi baru (konfirmasi)

5. Guru memberi kesempatan bertanya kepada siswa apabila terdapat materi yang belum dipahami (konfirmasi)

6. Guru mengadakan post test terkait materi yang telah dipelajari (konfirmasi)

\section{Tahap ketujuh: Penutup}

1. Guru dan siswa menyimpulkan hasil pembelajaran yang telah dipelajari.

2. Tindak lanjut dan informasi pertemuan berikutnya. 


\section{Homework:}

Siswa membaca buku terkait bank dan non bank

Setiap kelompok mendapatkan tugas wawancara dan observasi dilingkungan masing-masing terkait materi yang dipelajari

4. Salam penutup

Karakter: tanggnng jawab, saling menghargai pendapat, percaya diri, adil

Sumber Ajar

1. Lingkungan sekitar

2. Power point materi fungsi, sistem, produk bank dan non bank

3. Buku ajar modul ekonomi kelas X SMA penulis Yuli Eko, buku-buku terkait materi yang dipelajari

4. Website berbagai sumber terkait materi yang dipelajari

5. Artikel Solopos atau Kompas terkait materi

6. Lembar kerja siswa

Alat

Kertas hvs, laptop, LCD, barang, alat-alat tulis

Teknik dan bentuk Instrumentasi

\begin{tabular}{|l|l|}
\hline Teknik & Bentuk Instrument \\
\hline Pengamatan sikap & Lembarpengamatan sikap \\
\hline Tes unjuk kerja & Tes uji praktek kerja \\
\hline Tes tertulis & Tes uraian dan pilihan \\
\hline
\end{tabular}

Contoh instrument

a. Lembar pengamatan sikap

\begin{tabular}{|l|l|l|l|l|}
\hline \multirow{2}{*}{ No } & \multicolumn{1}{|c|}{ Aspek yang dinilai } & \multicolumn{2}{|c|}{ Kriteria } & \multicolumn{1}{|c|}{ Ket } \\
\cline { 3 - 5 } & A & B & C & \\
\hline 1 & Menunjukkan syukur kepada tuhan & & & \\
\hline 2 & $\begin{array}{l}\text { Menunjukkan ketekunan dan tanggung jawab dalam } \\
\text { belajar dan bekerja baik secara individu maupun } \\
\text { kelompok }\end{array}$ & & & \\
\hline 3 & Berani mengemukakan pendapat & & & \\
\hline 4 & $\begin{array}{l}\text { Memiliki sikap percaya diri dalam berinteraksi } \\
\text { dengan teman dan guru }\end{array}$ & & & \\
\hline
\end{tabular}


b. Lembar tes unjuk kerja

\begin{tabular}{|l|l|l|l|l|l|}
\hline \multirow{2}{*}{ No } & \multicolumn{1}{|c|}{ Aspek yang dinilai } & \multicolumn{2}{|c|}{ Kriteria } & \multicolumn{2}{|c|}{ Ket } \\
\cline { 3 - 6 } & & A & B & C & \\
\hline 1 & Siswa dapat bekerja sama dengan teman sekelompok & & & & \\
\hline 2 & Siswa mampu menjawab pertanyaan & & & & \\
\hline 3 & Siswa dapat melakukan kunjungan untuk pengamatan & & & & \\
\hline 4 & Siswa mampu mengerjakan tugas dengan tepat waktu & & & \\
\hline
\end{tabular}

c. Lembar test tertulis

1. Sebutkan jenis-jenis bank berdasarkan kepemilikannya...

2. Bagaimana perkembangan fungsi dan peranan bank...

3. Sebutkan lembaga-lembaga keuangan bukan bank...

4. Sebutkan perbedaan bank syariah dan bank konvensional...

5. Sebutkan perbedaan lembaga keuangan bank dan lembaga keuangan bukan bank...

\section{PENILAIAN}

Rubrik Penilaian Klasifikasi

\begin{tabular}{|l|l|l|l|l|l|}
\hline No & Kriteria & Bobot & A & B & C \\
\hline 1. & Ketepatan jumlah betul & $60 \%$ & $100 \%$ benar & $90-60 \%$ & $50 \%$ ke bawah \\
\hline 2. & $\begin{array}{l}\text { Keaktifan, kreatifitas, } \\
\text { kedisiplinan, tingkah } \\
\text { laku }\end{array}$ & $40 \%$ & Amat baik & Baik & Kurang \\
\hline Rubrik presentasi proyek & Bobot & A & B & C \\
\hline No & Kriteria & $40 \%$ & Baik & Sedang & Kurang \\
\hline 1 & Kualitas proyek & $30 \%$ & $\begin{array}{l}\text { Terarah, } \\
\text { jelas }\end{array}$ & $\begin{array}{l}\text { Biasa } \\
\text { saja }\end{array}$ & Kurang jelas \\
\hline 2 & Alur penjelasan & $20 \%$ & Jelas & $\begin{array}{l}\text { Biasa } \\
\text { saja }\end{array}$ & Kurang \\
\hline 3 & Intonasi suara & & Peneliti/Pelaksana \\
\hline \\
Guru Ekonomi & & Ahmad Nasir Aribowo S.Pd \\
\hline
\end{tabular}




\section{Daftar Pustaka}

Chien Liu, Tzu dkk. 2009.The effects of mobile natural-science learning based on the 5E learning cycle: A case study. Journal Educational Technology \& Society. Taiwan: Institute of Graduate Institute of Learning \& Instruction, National Central University, Taiwan // 2Institute of Education, National Chiao Tung University, Taiwan // 3 Taipei Municipal Shi-Dong Elementary School, Taiwan // 4 Department of Nature Science, Taipei Municipal University of Education.

Hsiao, Hsien Sheng dkk.2010. ocation Based Services for Outdoor Ecological Learning System: Design and Implementation. Educational Technology \& Society. Taiwan: Department of Technology Application and Human Resource Development, National Taiwan Normal University, Taipei, Taiwan 1 Department of English, National Taiwan Normal University.

Witthaus, Gabrille. (2009). The Implication of SCORM Conformance for Workplace e-learning. Electronic Journal of e-Learning Volume 7 Issue 2 2009,hal 01 (183-190). England: Journal International New Leaf Training Network Ltd. 